\title{
Is offering cooking classes to medical professionals a new trend? We sure hope so.
}

\author{
Stacey J. Bell ${ }^{1 *}$, Dodie Rimmelin ${ }^{2}$, David O. Danesh ${ }^{3}$ and Shyam Akula ${ }^{2}$ \\ ${ }^{1}$ Peak Health, 110 Woodland Street, Reno, Nevada 89523, USA \\ ${ }^{2}$ Harvard Medical School, 25 Shattuck St, Boston, MA 02115, USA \\ ${ }^{3}$ Harvard School of Dental Medicine, 188 Longwood Ave, Boston, MA 02115, USA
}

It is irrefutable that lifestyle accounts for $80 \%$ of chronic disease risk, such as cardiovascular disease, type-2 diabetes, and many forms of cancer [1,2]. The adoption of four lifestyle changes can mitigate risk: not smoking, getting regular exercise, maintaining a healthy body weight, and consuming a healthy diet. Even in populations with high genetic risks, benefit from adopting these same habits are significant [3].

Despite the overwhelming evidence, two of four key lifestyles components - weight management and diet - are virtually ignored in medical and dental school curricula. Of the 133 medical schools in the United States, $71 \%$ fail to meet the recommended 25 hours of teaching nutrition set by the National Research Council's Committee on Nutrition in Medical Education [4]. Those that do teach nutrition offer an average of only 19 hours [5]. Thus, US medical schools fail to prepare future physicians for everyday nutrition challenges in clinical practice. It cannot be a realistic expectation for physicians and other healthcare providers like dentists to effectively address healthy eating and obesity,when they are not given the knowledge and tools to do soduring their school and residency training.

We believe that the nutrition education for physicians and other health professionals-in-training is essential and that it is best to combine a didactic approach with a practical one via a cooking course. However, we are aware of only a handful of medical schools that offer cooking classes. For example, at the University of Chicago Medical School, medical students are required to take a four-week cooking course led by two post-residency physicians. The program combines both nutrition education and cooking [6]. At Tulane, Dr. Timothy Harlan, known in the food media world as Dr. Gourmet, is the executive director at the Goldring Center for Culinary Medicine, where the cooking classes are held for medical students [7]. The focus of the program, consisting of seven, 4-hour classes, is on practical talk about food, enabling physicians to teach patients everyday skills in how, what, and why to cook. The program emphasizes the use of low-cost, healthy ingredients. The program developed a curriculum, which has been sold to other medical schools.

The University of Massachusetts Medical School offers a studentinitiated, joint cooking program with the School of Nursing [8]. The five-week program teaches hands-on cooking skills and real nutritional values of foods rather than just the biochemical effects in the body. The goal is to supplement what is taught in the formal curriculum with practical ways for the students to improve their own dietary habits, develop confidence in counseling patients about nutrition, and become healthier. Most of the recipes take about an hour or less to cook, and are made in big batches that can be frozen. The didactic side includes an introduction to nutrition; macronutrients and meal planning; dietary considerations for chronic conditions like cardiovascular disease, type2 diabetes, and weight management; and alternatives like gluten-free and dairy-free cooking. Once the meal is cooked and everyone is seated for dinner, each class ends with discussion of patient cases presented by faculty advisor and dietitian.

A new comer to incorporating cooking and nutrition education is a course at the Harvard Medical, Graduate, and Dental Schools, which began the student-run activity in January 2016. The concept was started by Laurent Adamowicz, who is an entrepreneur, former food industry executive, member of the Nutrition Round Table at the Harvard T. $\mathrm{H}$. Chan School of Public Health, and avid promoter of healthy eating. Several hurdles had to be crossed before the program started. First, the students sought approval from the Dean of Students at the medical school, and this led to all medical, dental, and $\mathrm{PhD}$ students being invited to sign up for cooking classes. Second, the Arts and Humanities Initiative at Harvard Medical School, which oversees some extracurricular activities at the Medical and Dental schools, provided the students with a small grant to cover cooking equipment expenses [9]. Third, the program sought seed money for start-up costs, which was provided by EChO-Eradicate Childhood Obesity foundation, a public charity started by Mr. Adamowicz [10].

Another consideration was a proper location for cooking events. Students are not provided meals but have access to 14 kitchens throughout the 324-room student dorm. Students in the cooking program make arrangements for a large group, usually 10-20 students, to use the kitchen for the evening,though not exclusively. The cooking classes meet every two weeks for about four hours. Students bring a chopping board, knife, and may sign-up to bring some of the ingredients or contribute $\$ 7$ to cover the food costs. Menus are selected following discussion between student organizers and Mr. Adamowicz. Students keep a log of the recipes, including special ingredients and tips on preparation.

Like students attending cooking classes elsewhere in medical schools, the Harvard students stated that they wanted to learn to cook healthier meals for themselves and to provide better information to their patients. The Harvard program's focus is on preparation of

Correspondence to: Stacey J. Bell, Chief Science Officer, Peak Health, 110 Woodland Street, Reno, Nevada 89523, USA, E-mail: staceyjbell@yahoo.com

Received: December 14, 2016; Accepted: January 02, 2017; Published: January 06, 2017 
meals that are always healthy, easy to make, and not pricey. These criteria are what students and many patients are looking for. Students learned that often it is less costly to cook fresh foods than it is to buy even the relatively cheap fast food items. For example, the instructor recommended purchasing and roasting a whole chicken rather than buying chicken nuggets at a supermarket or a fast food restaurant. Cooking a whole chicken is not only more cost effective but also provides a second meal.In terms of health, the students are guided on reducing salt in cooking, using naturally sweet ingredients like dried fruits instead of those with added sugar, and using olive oil in lieu of other vegetable oils or butter.The preparation time varies among the meals, but the group finds the time as a way to relax and socialize. After the meal is cooked-that is protein, vegetable, salad, and dessert-the students eat in the small kitchen area, and often ask friends to join the group. Since January 2016, students in the cooking class completed over 60 hours of cooking and nutrition instruction.

Whether adding a cooking course to a didactic nutrition program in medical or dental education will improve the ability of doctors and dentists to give better nutritional advice to their patients remains to be tested. However, around the country, busy students are making the time to learn new cooking skills, prepare healthy meals, and socialize over cooking and sharing meals. We envision a future where the doctors, dentists, and other healthcare professionals understand what it means when a patient is prescribed a heart-healthy or diabetic diet, provide dietary advice, and be able to share cost-effective and delicious recipes and food preparation tips. This will lead to better overall health of the patients.

\section{Conflict of interests}

Dr. Bell works for a company that manufactures nutrient-dense foods.

\section{References}

1. Willet WC, Koplan JP, Nugent R, Dusenbury C, Puska P, et al. (2006) Prevention of Chronic Disease by Means of Diet and Lifestyle Changes. In: Jamison DT, Breman JG, Measham AR, et al., (eds.), The International Bank for Reconstruction and Development/The World Bank; New York: Oxford University Press. [Crossref]

2. Ford JS, Bergmann MM, Kroger J, Schienkiewitz A, Weikert C, et al. (2009) Healthy Living Is the Best Revenge Findings from the European Prospective Investigation into Cancer and Nutrition-Potsdam Study. Arch Intern Med 169: 1355-1362. [Crossref]

3. Khera AV, Emdin CA, Drake I, Natarajan P, Bick AG, et al. (2016) Genetic Risk, Adherence to a Healthy Lifestyle, and Coronary Disease. N Engl J Med 375: 2349-2358

4. Adams KM, Butsch WS, Kohlmeier M (2015) The State of Nutrition Education at US Medical Schools. J Biomed Educ 2015: 357627

5. Staff writer (2015) What's at stake in nutrition education during med school. https:// wire.ama-assn.org/education/whats-stake-nutrition-education-during-med-school

6. Eng M (2015) A Dose of Culinary Medicine Sends Med Students To The Kitchen. Chicago. http://www.npr.org/sections/thesalt/2015/07/01/419167750/a-dose-of-culinarymedicine-sends-med-students-to-the-kitchen

7. Farr C (2015) If Doctors Learned to Cook, They Might Give Better Advice. Tulane http://www.npr.org/sections/health-shots/2015/12/26/460803440/if-doctors-learnedto-cook-they-might-give-better-advice

8. Gay S (2015) Cooking class aims to prepare medical students for better patient care. Future doctors learn by doing in Cooking for the Everyday Eater, which features easy, nutritious and delicious recipes. http://www.umassmed.edu/news/news-archives/2015/12/ cooking-class-aims-to-prepare-medical-students-for-better-patient-care/

9. Arts and Humanities Initiative at Harvard Medical School. http://artsandhumanities hms.harvard.edu/

10. EChO-Eradicate Childhood Obesity Foundation. http://echoforgood.org/about-us

Copyright: $\odot 2017$ Bell SJ. This is an open-access article distributed under the terms of the Creative Commons Attribution License, which permits unrestricted use, distribution, and reproduction in any medium, provided the original author and source are credited. 